\title{
Urban configuration, accessibility and property prices: a case study of Cardiff, Wales
}

\section{Yang Xiao ${ }^{a}$, Scott Orford ${ }^{b^{*}}$, Chris Webster ${ }^{\mathrm{c}}$}

a: College of Architecture and Urban Planning, Tongji University,1239 Siping Road, Shanghai, 200092, China b: School of City and Regional Planning, Cardiff University, Glamorgan Building,King Edward VII Avenue, Cardiff, Wales, CF10 3WA

c: Faculty of Architecture, The University of Hong Kong, 4/F, Knowles Building, Pokfulam Road, Hong Kong

* Corresponding author: Dr. Scott Orford, orfords@cardiff.ac.uk,02920875272. 


\begin{abstract}
The specification of locational attributes in hedonic house price models has traditionally been problematic. Whilst many studies use similar sets of structural attributes the range of locational attributes can be diverse and inconsistent both in their identification and in their measurement. To address this problem, studies have adopted concepts relating to urban configuration such as the monocentric city and the access-space trade-off model, and later multi-centric and multiple accessibility models, to structure their enquiry. This has lead to issues relating to a priori variable specification using geometrically defined accessibility measures that can also lead to problems such as spatial auto-correlation. In this research, we investigate the use of network accessibility metrics in hedonic house price research using Cardiff, Wales as a case study. We hypothesize that a network modelling approach to measuring accessibility will improve performance compared to conventional geometrical specifications. We find that estimating centrality variables across a variety of spatial scales allows the impact on property prices of urban configuration to be more accurately modelled. The research shows that not all dimensions of accessibility can be adequately captured by network measures and that conventional geometric measures of accessibility can add additional explanatory power in certain circumstances. The research also demonstrates the importance of modelling urban configuration at the individual property level to prevent the loss of information when using aggregated data.
\end{abstract}

Keywords: network analysis, space syntax, locational externalities, urban configuration, accessibility, hedonic house price models 


\section{Introduction}

Neo-classical micro-economic theory (Alonso, 1964), which developed classical Ricardian value theory, emphasises the 'access-space' trade-off as a fundamental urban law. In this tradition, at equilibrium, land-users are indifferent to location because higher transport costs balance lower land costs in less accessible parts of the city. This insight has fed through into housing research, with the understanding that land and accessibility are substitute hedonic factors in determining house prices ( (McDonald, 1987, Richardson et al., 1990, Heikkila et al., 1989, Waddell et al., 1993, Orford, 2000, Orford, 2002).

The specification of locational attributes in hedonic house price models has traditionally been problematic as, unlike structural attributes (Follain and Jimenez, 1985, Sirmans et al., 2005), their effects on property prices are less tangible and less understood. They are difficult to conceptualise and measure; they can operate at various spatial scales; and they are influenced by many interrelated external factors (Orford, 2002). As a result, whilst many hedonic house price studies use similar sets of structural attributes, the range of locational attributes can be diverse and inconsistent both in their identification and in their measurement. To address this problem, studies have adopted concepts relating to urban configuration to structure their enquiry. In early studies, accessibility to the CBD was typically the major determinant of location-specific land values and site rents in this class of model. These early studies are considered seminal in urban theory but have given way to more nuanced studies that better capture the multi-centric and network geometry and topology of urban configuration and locational advantage (McDonald, 1987). A variety of accessibility measuring devices has been adopted more recently to capture the locational externality effect more sensitively than the purely Euclidean distance (Niedercorn and Ammari, 1987, Hoch and Waddell, 1993). Specific approaches include studies specifying accessibility indexed by travel time(Landau et al., 1981), job accessibility (Osland and Thorsen, 2008), railway infrastructure improvement (Debrezion et al., 2011), and systemic street network connectivity (Matthews and Turnbull, 2007, Enström and Netzell, 2008).

One characteristic of studies that measure accessibility to specific points of benefits and disbenfits is that the specific configuration of the study area is used to help frame and design the model specification. The locational externalities hypothesized to be influential are identified and their functional relationships with property prices (such as their distance decay) are specified a priori. In a multi-centric conceptualisation of urban configuration, this requires multiple variables capturing each externality effect and this can cause problems of multi-collinearity if the variables are correlated across space leading to violation of the model's assumptions; for instance, if multiple 
distance measures are used to capture externality effects. Moreover, the exact nature of urban configuration in relation to the housing market and its impact on property process is often not know a priori and hence it is often impossible to theorize which of the many possible locational externalities are important and how they should be specified. Even if it is possible to specify a priori the likely specific locational influences on house prices, the researcher must make an arbitrary decision about which ones to measure.

In this paper we take an approach to resolving these issues by exploring the intuitive hypothesis that important information about urban configuration is contained in the urban street network and can be captured from accessibility metrics measured from a topological network model of the street layout. Most hedonic models fail to take note of essential spatial information in the street layout: network connectivity, network distance, angular distance and so on, which in turn, have been shown to have a strong influence on pedestrian behaviour, congestion and other influences on property price (Porta et al., 2006a, Porta et al., 2009, Porta et al., 2012, Chiaradia et al., 2012). One way of looking at this is that street network connectivity metrics are a proxy for the multiple dimensions of human interactions that produce value in a city. They measure general accessibility rather than specific accessibility and may be supposed to be more powerful predictors of locational valuations as a result (Webster, 2010).

We test this hypothesis using the Welsh capital city of Cardiff as the study area. A sub-set of the Cardiff street network is modelled using space syntax methodology and various measurements of network accessibility are taken from the model to form locational variables in a hedonic model of house prices, which is used to test the following hypotheses:

1. Accessibility metrics derived from a topological network model improves hedonic model performance compared to conventional geometrical measures of accessibility, in respect of:

a. Measures of explanatory power

b. A reduction in multicollinearity, heteroscedasticity and spatial autocorrelation

c. Improved accessibility coefficient estimates in terms of reducing counter-intuitive sign and statistical insignificance

2. Accessibility metrics derived from a topological network model better capture the complexity of the access-space trade-off model of property prices compared to conventional geometrical measures in respect of multi-scaled, multi-centric urban areas 
The paper is divided into five sections. In section two we provide a brief review of previously published work relating to the specification and measurement of accessibility in hedonic research. The case study area, data, methods of constructing accessibility measures and the hedonic model specification are presented in section three. Results are presented in section four, where we estimate three models using individual property level data. Section five summarizes the findings and concludes with a discussion of network approaches to modelling urban configuration in hedonic house prices models compared to more conventional geometrical approaches.

\section{Accessibility measures in hedonic research}

\section{Conventional geometric measures}

In access-space trade-off models, transportation costs are traded off against land rents. Improvements in transportation infrastructure are assumed to reduce commuting costs, releasing more from a household budget to spend on land rent (Alonso, 1964, Muth, 1969, Mills, 1972). However, Alonso's (1964) monocentric model is clearly one pertaining to a particular historical phase in a city's evolution and does not adequately capture accessibility value where workplaces are not solely located in the city center (McDonald, 1987), or where trips to work form a declining share of overall household travel. The multi-centric nature of many housing-market areas makes onedimensional separation measures like physical distance and travel time from a distinctly defined center problematic. The presence of multiple-worker households and multiple workplaces motivated the search for alternative separation measures. Heikkila et al (1989) found distance to the CBD to be insignificant, with the estimated coefficient having a counter-intuitive positive sign in a property price hedonic model of Los Angeles in 1980. They concluded that the impact of workplace accessibility has been overemphasized. Richardson et al. (1990) note that the effect of distance to the CBD may have declined, findings that the distance coefficient for Los Angeles CBD was significant and negative in a dataset from 1970. Waddell et al. (1993) emphasized the importance of including distance to secondary employment centres, and found both a strong and significant asymmetric CBDgradient and strong local effects from non-CBD employment centres. Orford (2002) specified a multilevel hedonic model to evaluate locational externalities, examining a range of locational effects on property prices. In terms of property-level externalities, the research used distance to the CBD, motorway exits, railway stations, shopping centres, and suburban employment centres. It also considered proximity to non-residential land uses such as parks, schools, industry, commercial, local shops, recreational centres and cultural and educational centres. The results showed a complex 
geography of locational externality effects, with areas of positive and negative externalities in juxtaposition across highly localised areas.

Researchers have experimented with a wide variety of alternative measures. On approach has been to measure transport costs more accurately (the traditional distance to CBD measure is a simple approximation of travel cost). Gibbons and Machin (2005) explored the effects on property prices of a transport innovation for households in London in the late $20^{\text {th }}$ century. They defined rail access in two ways: distance to a station and service frequency at the nearest station. Distance changes induced by the transport innovation were associated with price changes and the price effect was large compared to the monetary valuation of other local amenities. Adair et al. (2000) examined the relationship of housing price and accessibility in Belfast urban area, adopting a gravity model and calculating an accessibility index for locations to various opportunities by different types of vehicle. The measure was a weak but significant predictor of house prices. Osland and Thorsen (2008), utilized a hedonic model to confirm that gravity-based labour-market accessibility contributes to property prices. Significantly, they found that labour-market accessibility is not an adequate alternative to distance from the CBD. Woo and Webster (2013) examined the trade-off between publicly provided and privately provided civic goods in determining condominium prices in Seoul, testing the hypothesis that the club-goods within condominium developments are a substitute for open access public goods and therefore a substitute for centrality as conventionally modelled. They found strong evidence of a substitution effect for some types of goods, including local green space and concluded that a 'city of residential clubs' has significantly different locational dynamics compared to the conventional city in which public goods are supplied by the state.

Matthews and Turnbull (2007) examined how street layout affects property value using network centrality derived from a network analysis of east and west Washington. They found network centrality measured within a 1400 feet walking distance radius to be significantly correlated with house price in both west and east samples, but the coefficient signs were opposite in the two samples. They concluded that the portion of house value contributed by street layout critically depends upon the context of the surrounding development pattern. Enström and Netzell (2008) examined urban street layout impact on commercial office rents in Stockholm and found that it had a positive impact on office rent. Empirical evidence of the association between property prices and street network connectivity are limited; hence the focus of our paper, which attempts to take this tradition of spatial analysis of housing markets a step further. 


\section{Network measures of accessibility}

Stewart (1947) firstly used the concept of graph theory defining gravitational potential as the weighted sum of forces. Hansen (1959) started with a graph theory view of the spatial system, identifying accessibility as a key element in spatial interaction; while Haggett and Chorley (1969) established a centrality analysis approach to analysing spatial relationships.

Recently, Batty (2009) summarized three mainly types of accessibility in mainstream urban scholarship. First concerns potential 'opportunities' (Hanson 1959, Osland and Thorsen 2008), measuring the size of the opportunities at a location and inversely moderating this with the distance or time taken to access those opportunities. The second type of accessibility is normally applied in traffic models and measures the sum of the shortest routes in a planar graph connecting a location to all other locations (Debrezion et al. 2011). High accessibility is normally associated with minimum distance, travel time and travel cost. It is noted that such metric geographical network analysis, nodes or vertices are defined as the intersection or junction of streets, while the links or edges are street segments linking two intersections, which is widely accepted as the prime approach. By contrast, a third type of accessibility is based on the dual approach, which defines road intersections as links and street segments as node (Hillier and Hanson, 1984, Porta et al., 2006b, Porta et al., 2009, Jiang and Claramunt, 2002, Jiang and Claramunt, 2004).

The use of the dual approach as applied in the Space Syntax network analysis software has come under criticism. For example, Ratti (2004) finds several inconsistencies in the 'axial maps' that are used in Space Syntax to model the urban spatial structure. They are, he suggests, not objective, consistent or unique and suffer from "cross-error", which means the value could shift when the system changes. Furthermore, Steadman (2004) points out that the space syntax method seems to be problematic at the large urban scale. Movement along a straight but congested urban street is slow and requires the expenditure of energy. The urban traveller might be expected to choose the shortest metric distance for lower energy cost rather the fewest changes of direction.

In response to these criticism, Hillier and Penn (2004) suggest that a metric radii search measurement imposed on the topological analysis will ease the cross-error of Ratti (2004). This position is also accepted in the studies of Porta et al $(2006,2009)$. Turner et al. (2005) proposed an algorithmic solution to the objectivity criticism of Ratti, by demonstrating the possibility of a unique axial line map. Turner (2007) also found that using standard road-centre lines instead of lines of 
sight, and angular separation as a friction measure gave a stronger correlation between network connectivity and observed vehicular flows than the conventional space syntax measures. In our study, we follow Turner's (2007) approach, using the road central line (ITN) to capture the spatial information contained in street layout-centrality. We measure the fiction of distance by angular separation (we aggregating the degrees of turn along a route).

In this study, we used two metrics of network centrality: closeness and betweenness. Behaviourally, these are based on two trip-choice criteria that an individual has to make while traversing the road network; selecting a destination and selecting a route to get to the destination. The former is based on how easy is it to get to a destination, also termed the to-movement component. More accessible destinations on this measure are more likely to be selected as locations for higher activity uses, such as shops. The betweenness measure the places that an individual has to pass through the get to a destination, and scores more highly those parts of the network where more people pass through. It is also termed the through-movement component

In graph-theoretic terminology, the to-movement potential is termed 'closeness' (integration in space syntax) and measures the ease with which a destination may be accessed within a network. Space syntax Integration analysis models the mean distance between origin and all possible destinations within network radius R. It measures the extent to which a road segment is close to all other road segments along the shortest distance of the street network and is formalised by equation (1):

Closeness for a road segment $\mathrm{i}$ is defined as:

$$
\text { Closeness (Integration })_{i}=\frac{N-1}{\sum_{j=1 ; j \neq i}^{N} d_{i j}}
$$

Where $\mathrm{N}$ is the total number of road segments in the network, and $d_{i j}$ is the shortest distances between road segment $i$ and $j$.

The through-movement potential is captured by the graph-theoretic measure of betweenness (Freeman, 1979). This is Route Choice (or Choice) in the space syntax literature and measures the degree of potential for movement through a segment of the road network. In contrast to integration, which measures the relative ease of reaching potential destinations, the betweenness index indicates how often people are likely to pass through a particular route and therefore which parts of the road network will be the busiest. Space syntax choice analysis assumes that people will travel from two points on the network along the shortest path based on topological distance-"turn". 
Choice at radius $\mathrm{R}$ measures the number of shortest paths by turns connecting all pairs of road segments in the network with a maximum length of the path being R. A road segment is more central, and thus has more potential for through traffic, the larger the number of shortest paths connecting it to the network. Betweenness for a road segment $i$ is defined as:

$$
\text { Betweenness }(\text { choice })_{i}=\frac{1}{(N-1)(N-2)} \sum_{j=1 ; k=1 ; j \neq k \neq i}^{N} \frac{n_{j k}(i)}{n_{j k}}
$$

Where $n_{j k}$ is the number of shortest paths between road segment $\mathrm{j}$ and $\mathrm{k}$, and $n_{j k}(i)$ is the number of these shortest paths that contain segment $\mathrm{i}$.

\section{Study area and data assemblage}

The study area is the Welsh capital city of Cardiff. Cardiff was chosen because of data availability, the authors' knowledge of the Cardiff housing market and the fact that Cardiff is very similar in size and form to other UK cities, allowing for the possibility of generalising the results. The study is limited to an area $6 \mathrm{~km}$ by $4 \mathrm{~km}$ stretching from the north of Cardiff city centre to the edge of the suburbs (Figure 1). This area is representative of the housing stock in Cardiff and includes the Victorian and Edwardian terraces of the inner city and the inter-war and post-war semi-detached and detached houses in the suburbs. It includes recent infill development of flats in the inner-city area as well as some new build on the edge of the city. From the perspective of urban configuration, there is a dualcarriageway (A48) which divides the study area into the inner-city and suburbs, with each sised of the division displaying different social and built-form characteristics. The area has been used in previous property price research (Orford, 2000, Orford, 2010, Orford, 2002).

[FIGURE 1 HERE] 
Property price data comes from the England and Wales Land Registry and a service license was acquired to use the following data: full address of the property, price paid, sale date, property type (detached, semi-detached, terraced, Flat/Maisonette), whether it was new-build and tenure (freehold or leasehold). These data were acquired for 16,297 properties sold in the study area for the period from 2001 to 2007 (an average of 2000 transactions per year) and were attached to Ordnance Survey (OS) Mastermap Address Layer that provides grid co-ordinates for each property to a resolution of less than 1 metre. Given the paucity of Land Registry data (and structural attribute data for individual properties in England and Wales), floor area was estimated for each property in the property price database using a methodology described in Orford (2010) and briefly outlined here. The building footprints for all the properties in the study area were extracted from OS Mastermap topographic layer and linked to the address layer. Heights of each property was obtained using Environment Agency LIDAR data that uses airborne laser scanning to create a digital surface model of the study area. The height data allowed the number of stories of each building to be calculated and this information was used with the building footprint data to estimate the floor area of the property. The estimated floor area data were calibrated against a sample of properties where the actual floor area had been obtained from estate agent surveys and was referenced to property type. This showed a close correspondence between the estimated floor area and the actual measures of floor areas in the sample of properties, although there were some differences reported for flats, principally due to conversions and sub-divisions of larger properties. Floor area is perhaps the most important structural attributes in determining house price (Sirmans et al., 2006), and tends to be highly correlated with other structural attributes such as number of rooms, size of garden etc. and so its inclusion will mitigate, to some degree, these missing structural attribute variables. The Office of National Statistics (ONS) Output Area Classification (OAC) data was used to capture small area demographic and socio-economic characteristics (Vickers and Rees, 2007). The OAC classifies each census Output Area (OA) into one of seven groups: blue collar communities, city living, countryside, prosperous suburbs, constrained by circumstances, typical traits and multicultural. An OA is the smallest census unit and corresponds to approximately 125 people and 40 households and there were 332 OAs in the study area.

\section{Constructing accessibility variables}


Two distinct sets of accessibility variables were constructed for the research. The first set pertain to traditional geometric measures of accessibility and, following the housing price studies of Cardiff by Orford (2000; 2002), these were calculated using the natural log of network distance from each property to the city centre, to Cardiff Bay and to significant local amenities including the main city park (Bute Park), the University Heath hospital and a suburban park located in the study area (Roath Park). The second set pertains to network accessibility metrics, using street centre line from Ordnance Survey Mastermap ITN and the confeego 1.0 network analysis software (www.spacesyntax.org). Network accessibility values were calculated for each street network segment, measuring closeness and betweenness at the following radii: $400 \mathrm{~m}, 800 \mathrm{~m}, 1200 \mathrm{~m}, 1600 \mathrm{~m}$, $2000 \mathrm{~m}, 2500 \mathrm{~m}, 3000 \mathrm{~m}, 4000 \mathrm{~m}, 5000 \mathrm{~m}, 6000 \mathrm{~m}, 7000 \mathrm{~m}, 8000 \mathrm{~m}, 10000 \mathrm{~m}$ and global $\mathrm{Nm}$ (the entire study area). These can be associated with different uses of the road network, for example, $400 \mathrm{~m}$ $1200 \mathrm{~m}$ is walking scale and $1600 \mathrm{~m}-2000 \mathrm{~m}$ is cycling or running scale, while above $2500 \mathrm{~m}$ is car scale. Through testing the different choice radii on housing price in our study area, we can estimate what kind of network scales affect property prices.

In total, fifty-five variables were prepared for the hedonic models: twenty-one dummy variables and twenty-four continuous variables (summarized in Table 1). Very few properties are new build and four-fifths are freehold tenure. Terraced houses make up the largest portion (53\%) of properties in the sample, with semi-detached houses the second largest portion (21\%), followed by flats (17\%). Only $5 \%$ of the OAs in the study area are classified as 'constrained by circumstances' in contrast to $28 \%$ which are in the 'typical traits' and 'living in the city' categories. Between $11-15 \%$ of properties in the sample are recorded as having been sold in each of the years, with the exception of 2008, which represents only $1 \%$ of sales in the sample due to the large downturn in the housing market that occurred in that year.

\section{[TABLE 1 HERE]}

\section{Hedonic model specification}

The hypothesis being tested in this study is that the precise geometric and topological structure of the urban road network affects residential property prices and by testing their impact at various spatial scales we can begin to model the effect of urban configuration on those prices. We measure urban configuration using the network accessibility metrics described above and test their influence on property price, controlling for other structural and locational attributes of housing. 
The hedonic price model employed in this study is specified in the following general form:

$$
P_{i}=\alpha_{i}+\beta_{1} S_{i}+\beta_{2} C_{i}+\beta_{3} T_{i}+\beta_{4} D_{i}+\beta_{5} X_{i}+\varepsilon_{i}
$$

Where:

$\mathrm{P}_{\mathrm{i}}=$ Transaction price of residential property;

$\mathrm{S}_{\mathrm{i}}=$ Vector of property structural attributes;

$\mathrm{C}_{\mathrm{i}}=$ Classification of $\mathrm{OA}$;

$\mathrm{T}_{\mathrm{i}}=$ Year of transacted property price;

$D_{i}=$ Vector of geometric accessibility variables;

$\mathrm{X}_{\mathrm{i}}=$ Vector of spatial network accessibility metrics at different radii;

$\varepsilon_{\mathrm{i}}=$ Random error term

As is common in hedonic property price research, the log of the dependent variable is used (Malpezzi, 2003). This allows the interpretation of the coefficients to be in terms of percentage change of the housing attribute on the price of the property. It also reduces heteroscedasticity in the error terms (Diewert, 2003). The model was estimated in three forms: (a) classical hedonic house price variables plus conventional geometric accessibility variables (b) classic hedonic variables plus a full set of network accessibility variables (c) classic hedonic variables plus conventional geometric and network accessibility variables. As many hedonic house price researchers fail to report the results of diagnostic econometrics test we have performed a number of tests (Belsley et al., 2005) to ensure the assumptions of the hedonic model are not violated including: tests on leverage points and outliers (Cook's D, DFFITS), multicollinearity amongst the independent variables using the Variance Inflation Factor (VIF), a White test used to detect heteroscedasticity and Moran's I test (Cliff and Ord, 1981) to assess spatial autocorrelation in the error terms.

\section{Analysis and discussion}

Three models were estimated in order to investigate the impact of street-network morphology on property prices. The first of the three individual level data models (Model I) was estimated using the structural and neighbourhood variables and the geometric accessibility variables found in conventional hedonic property price research. As is typical in such research, strong correlation 
existed between the five accessibility variables and they were also moderately correlated with the neighbourhood variables. As a result, two of the five accessibility variables (log distance to Bute park and log distance to Cardiff Bay) were statistically insignificant at the $5 \%$ level when included simultaneously in the model. Therefore only three accessibility variables were retained with the final model reported in Table 4.1. The log likelihood is -5783 , the corrected Akaike Information Criterion (AIC) is -34635 , and the F-statistic is significant at the $1 \%$ level or less, all indicating that the model fits the data well and that each independent variable is significantly linear. The adjusted R-square statistic is 0.63 which is typical of hedonic house price models. All the independent variables are statistically significant at the $1 \%$ level or less and the VIFs indicate that multicollinearity is not a problem. However, the White test reveals the presence of strong heteroscedasticity in the error terms and so the prediction of the model is poor and Moran's I also reveals significant positive autocorrelation, suggesting that the coefficient estimates are unreliable, leading to over estimation.

\section{[TABLE 2 HERE]}

As theory suggests, property prices are found in this model to increase as floor area increases; new build properties are found to have a premium; and terraced, semi-detached and detached houses are increasingly more expensive than the omitted property type dummy 'flat'. Freehold tenure commands a premium over leasehold tenure. The premiums for living in the different neighbourhoods are in comparison to the omitted neighbourhood type dummy 'multicultural communities'. Hence properties in 'blue collar' and 'constrained by circumstances' neighbourhoods are slightly cheaper than in 'multicultural community' neighbourhoods whilst properties in 'prosperous suburbs' are substantially more expensive. There is very little difference in the premiums for properties in neighbourhood characterized by 'typical traits' or 'living in the city'. The year variables reveal continuous property price inflation since 2000 (the omitted dummy variable), the substantial increase in prices between 2002 and 2004 and the flattening off and start of property price decline in 2008. In terms of accessibility, log distance to the city centre has a negative relationship with property prices as predicted by the access-space theory of land-values. Accessibility to Roath Park and to the Heath Hospital has the anticipated negative relationship with property prices, indicating that they act as positive externalities. The log-log specification means that the relationship between property price and accessibility can be interpreted as the price elasticity of distance. Hence a $1 \%$ change in distance to the CBD is associated with a $0.101 \%$ decline in property price or, alternatively, a doubling of distance from the CBD is associated with a $10 \%$ decline in property price. The percentage change is slightly larger for Roath Park, suggesting that it has a 
stronger affect on property price in the study area, and slightly smaller for Heath Hospital suggesting a weaker affect on property prices. These findings make intuitive sense to those familiar with the local housing market.

Model II was estimated using the network accessibility variables rather than the planar geometry variables. Here, closeness and betweenness measures are investigated at different radii in order to discover the spatial scale at which any network accessibility effects are most poweerful. The three planar accessibility variables were removed from the model and pairs of choice and betweenness variables for the fourteen spatial scales (radii) were entered one at a time into the model, the model was estimated, and the pair removed before repeating the process for each spatial scale. We used two statistical tests to help guide us in this process; the t-statistic and the corrected AIC statistic. Following Fotheringham et al. (2003) and their use of the t-statistic in geographically weighted regression (GWR) modelling, we use t-statistic values in excess of 2 here purely as an indicator of where potentially interesting relationships might occur rather than a test of statistical significance. This is because we are estimating a number of regression models and hence we are undertaking multiple hypothesis tests when we estimate the significance of the t-statistics. These tests are not independent either, as they re-use the same data for tests which are spatially close to each other. This will affect the probability of whether the t-statistic is significant at random and so the conventional approach of considering only the parameter estimates where the T-statistic is greater / less than 1.96 is not appropriate here (Byrne et al., 2009). A similar issue occurs with the estimation of GWR models, thus the adoption of the GWR approach to modelling here.

The AIC statistic is a goodness of fit measure that corrects for model complexity and can be used to compare the models with the same dependent variable and different independent variable subsets; it provides a measure of the information distance between the model which has been fitted and the unknown true model. The model with the lowest AIC is the one with the best predictive performance. In addition, and in the spirit of Fotheringham, et al (2003) who used AIC to determine the optimal bandwidth of kernel density estimates in GWR, we have used the AIC to check if the network accessibility variables in models estimated at consecutive spatial scales are equivalent and therefore add equivalent amounts of information (and thus the two models and hence the network variables are not statistically different). As a rule of thumb, models having their AIC within 3 are said to be equivalent. The differences in AICs in consecutive models are a lot greater than 3 suggesting that the network variables in consecutive models are not equivalent and are therefore statistically different. 
For brevity, Table 3 summaries the coefficient estimates and t-statistics for each pair of choice and integration variables for each spatial scale in the fourteen versions of the model, but not the other variables which had similar coefficient estimates to those in Model I. The AIC statistics, the White test statistics and the Moran I statistics are presented below the t-statistics and give an indication of the goodness of fit of the model and whether heteroskedasticty and spatial autocorrelation are present in the model's error terms. The adjusted R-square statistic is the same in all models and is similar to Model I and the VIF scores (not presented) are within the desired range.

The choice and integration measures are statistically significant at the $1 \%$ level or less at each spatial scale and the closeness coefficients have substantially larger T-statistics than the respective betweenness coefficients.

\section{[TABLE 3 HERE]}

Betweenness has a negative and closeness a positive relationship with property price. This is as expected, as betweenness indicates likelihood of congestion and closeness indicates ease of access to opportunities. In this way, the two network metrics neatly differentiate positive and negative network externalities. The radially unconstrained (city-wide) model for closeness is 0.001 (T-statistic 33.12) and for betweenness is -0.016 (T-statistic 10.98). The betweenness coefficients are substantially larger than the closeness coefficients for each spatial scale with betweenness varying between $-0.013(5000 \mathrm{~m})$ and $-0.019(2000 \mathrm{~m})$ with an average of -0.016 and closeness varying between less than $0.001(6000 \mathrm{~m})$ and $0.003(400 \mathrm{~m})$ with an average of 0.001 . Indeed, the closeness coefficients become smaller the larger the spatial scale whereas there is a trend for the betweenness coefficients to get larger with an increase in spatial scale.

Further insight comes from examining the pattern of T-statistics for different radii summarized in Figure 2. This reveals a bi-modal distribution with the T-statistics for closeness rising from 10.35 at $400 \mathrm{~m}$ radius to a peak of 37.05 at $3000 \mathrm{~m}$ radius before declining and then rising to a slightly larger peak of 40.49 at a $7000 \mathrm{~m}$ radius before falling to 36.69 at $10,000 \mathrm{~m}$ radius. A similar trend of Tstatistics is observed for betweenness, but with a negative sign reflecting the relationship of betwenness with property price, with a peak of -9.87 at $2000 \mathrm{~m}$ before declining and rising to a slightly larger peak of -10.93 at $7000 \mathrm{~m}$ before falling to -10.15 at $10,000 \mathrm{~m}$ radius. 


\section{[FIGURE 2 HERE]}

The model with the smallest AIC is with the network accessibility variables estimated at $7000 \mathrm{~m}$ and hence this is the model with the best predictive performance. In addition, the model estimated at a $3000 \mathrm{~m}$ radius has a lower AIC compared to models estimated at a number of consecutively smaller and larger radii. This suggests that although the model estimated at $7000 \mathrm{~m}$ is the best, the model estimated at $3000 \mathrm{~m}$ also provides a comparatively good fit with the data at a smaller spatial scale. The White test statistic and the Moran I statistic are both large and significant (at the $1 \%$ level) suggesting that heteroskedasticity and spatial autocorrelation are present in the error terms, although the size of the test statistics is smallest for the models estimated at the $3000 \mathrm{~m}$ and $7000 \mathrm{~m}$ radii suggesting that there has been a reduction in heteroskedasticty and spatial autocorrelation at these two spatial scales.

Model III was estimated using both network accessibility variables and the planar accessibility variables. The three planar accessibility variables are as in Model I and pairs of betweenness and closeness variables for the fourteen spatial scales (radii) were estimated as in Model II. As before, Table 4 summaries the coefficient estimates and T-statistics for each pair of betweeness and closeness variables for each spatial scale in the fourteen versions of the model as well for the three conventional accessibility variables. The adjusted R-square statistic was again the same for all models and is slightly higher than in Models I and II suggesting the two different types of accessibility measure capture independent externality effects. The AIC statistics are smaller than in Model II for the equivalent spatial scale suggesting that the model fits the data better when both types of accessibility measure are included. All the AIC statistics for consecutive models are greater than 3 indicating that the network variables in consecutive models are not equivalent and are therefore statistically different.

The relationship between the betweenness and closeness variables are similar to that in Model II except that the T-statistics and coefficients are smaller, indicating that the network variables in Model II capture some of the general accessibility effects. The betweenness variable is statistically insignificant at the $5 \%$ level at $400 \mathrm{~m}$ radius. The pattern of T-statistics for different radii summarized in Figure 3 continues to show a bi-modal distribution, although with smaller peaks than in Model II. The integration variables' T-statistics now peak at $2500 \mathrm{~m}$ radius $(26.47)$ and again at $7000 \mathrm{~m}$ radius with a slightly smaller T-statistic of 25.84 . The choice variables' T-statistics continue to peak at 
2000m (-6.86) and 7000m (-7.07) as in Model II. The model with the smallest AIC is that estimated at $2500 \mathrm{~m}$ suggesting that the accessibility variables measured at this spatial scale best fits the data. The AIC is also slightly smaller for the model estimated at $7000 \mathrm{~m}$ compared to models estimated at slightly higher and lower spatial scales. Similar to the previous models, the White test statistic and the Moran I statistic were both large and significant (at the $1 \%$ level) suggesting that heteroskedasticity and spatial autocorrelation are present in the error terms, although the size of the test statistics are smaller than in Model II for equivalent spatial scales suggesting that there has been a reduction in heteroskedasticty and spatial autocorrelation in Model III.

\section{[TABLE 4 HERE]}

[FIGURE 3 HERE]

The impact of the network accessibility variables can be further evaluated in comparison to the effect of the three conventional accessibility variables in the models. Table 4 and Figure 4 reveal that both distances to the CBD and to the hospital become insignificant $(p=0.05)$ with an increase in the spatial scales at which the network accessibility variables are measured. Accessibility to the CBD has the anticipated negative relationship with property prices at $400 \mathrm{~m}$ radius but this relationship becomes insignificant at radii of $2000 \mathrm{~m}$ and $2500 \mathrm{~m}$. The relationship with property prices becomes positive and significant between $3000 \mathrm{~m}$ and $5000 \mathrm{~m}$, with prices increasing with distance to the $C B D$, before the relationship becomes insignificant at spatial scales upwards of $6000 \mathrm{~m}$. Accessibility to the hospital follows a similar pattern, although the relationship with property price is insignificant between $800 \mathrm{~m}$ and $5000 \mathrm{~m}$ before becoming positive and significant at spatial scales upwards of $6000 \mathrm{~m}$. In comparison, the T-statistics for accessibility to the area's large park are generally constant and significant across all spatial scales, with the anticipated negative relationship between the externality and property prices.

\section{[FIGURE 4 HERE]}

We may therefore conclude that for the study area, property prices seem to be most sensitive to network accessibility metrics measured at a radii of $2000-3000 \mathrm{~m}$ and $7000 \mathrm{~m}$ (as these have the two largest T-statistics and the lowest AIC statistics) and that this is true for negative (betweenness) and positive (closeness) road network externalities. Given that the radii are measured as network distances, the $2000-3000 \mathrm{~m}$ radius corresponds to the local neighbourhood and modes of transport 
associated with walking and cycling and short trips in the car whilst $7000 \mathrm{~m}$ radius corresponds to public transport and car journeys within 15-20 minutes. Given that we omitted the conventional accessibility variables in Model II, we can assume the two network metrics at $7000 \mathrm{~m}$ radius are a proxy for accessibility to the city centre. Network configuration becomes less influential beyond the $7000 \mathrm{~m}$ scale as it extends into ex-urban areas and the parts of the city the other side of the CBD, which indicates that beyond this distance there is no more city-scale externality effects captured in property prices in our study area. This shows that optimal radius for measuring network accessibility is related to the size and shape of the study area. In this case, the urban configuration of the study area appears to be bi-centric in relation to the housing market, with peaks caused by externalities associated with local neighbourhood and city centre. This observation is strengthened by the conventional accessibility variables in Model III. Here, the significance of accessibility to CBD was affected by the inclusion of network accessibility variables, becoming statistically insignificant at the spatial scales where closeness and betweenness variables have the largest T-values (2000-3000m and $6000-10000 \mathrm{~m})$. This suggests that at these scales, network accessibility metrics capture the effects of access to the $\mathrm{CBD}$ and that the property price-distance curve is not continuously monotonic but has local peaks reflecting local neighbourhood centres. The statistical insignificance of accessibility to the hospital across the majority of the spatial scales suggests that the effects of this employment and service centre is better captured by the network variables. The significant but positive relationship with property prices at spatial scales beyond $6000 \mathrm{~m}$ suggests that living in proximity to the hospital has a negative effect on property prices once accessibility to local neighbourhoods and the CBD has been accounted for by the network variables. Finally, the statistical significance of accessibility to Roath Park across all the spatial scales indicates that the network accessibility variables do not substitute for all scale-specific externality effects and that these still need to be included in hedonic house price models. This is consistent with the idea that network metrics may be superior proxies for capturing the effects of general accessibility on land prices while large-effect single sources of externalities need to be separately modelled as special accessibility metrics. We note that general accessibility is itself an aggregation and averaging of many separate sources of negative and positive externalities (Webster 2010).

\section{Discussion and conclusions}

We have presented an investigation into the use of network accessibility measures in hedonic house price research, using Cardiff as a case study. It has revealed that a network approach to measuring accessibility in urban areas can improve a model's performance with respect to explanatory power 
and a reduction in heteroscedasticity, spatial autocorrelation and multi-collinearity compared to conventional geometrical measures of accessibility. Further improvements to model specification such as additional structural and locational attribute variables and weighting and spatial lag variables may reduce and remove the heteroscedasticity and spatial autocorrelation that currently exists in the models. By estimating network accessibility variables across a variety of spatial scales, we have demonstrated that the study area displays a bi-centric urban configuration with respect to property prices that corresponds to local and city-wide externalities. This makes theoretical sense for a city such as Cardiff that has a clearly identifiable CBD and more localised centres of employment, retail and commercial activity and strong city-wide amenity green space attractions. This may not be the case for larger British cities that have a more polycentric urban configuration.

Possibly our most novel finding is that the two network accessibility measures of closeness and betweenness, respectively capture positive and negative intra-urban externalities in a broad sense. This is all the more significant since (a) the two measures are systemic measures and (b) they can differentiate micro market areas created by many local negative externality effects.

The research has shown that such variables can be a better substitute for some conventional geometric measures of general accessibility such as distance to the CBD; but that geometric measures to more specific locational externalities, such as a major park, are still required. Moreover, analysing the influence of the city's major hospital on property prices in the final individual level model we find that the interaction of network and conventional accessibility variables can unpack both the positive and negative externality effects of specific locational attributes that occur at different spatial scales without having to specify this functional relationship a priori. This, we suggest is another important and novel finding.

In future research in this area we intend to apply the techniques to larger cities with more complex urban configuration to see if it is possible to identify multiple peaks in the closeness and betweeness coefficients at various spatial scales relating to a polycentric urban form. It is also important to begin to better understand the precise nature of betweenness and closeness variables in terms of the specific locational externalities that they are capturing at different spatial scales. This will involve exploring spatial correlations of the network variables with conventional accessibility variables across the different spatial scales and across the city to determine when network accessibility variables make a good substitute for the conventional measures of locational externalities and when they do not. 
Finally, by bringing two genre of spatial analysis together (network analysis of street layouts comes from both an architectural and transport planning tradition, while CBD-accessibility and similar, come from urban economics), it will be possible to develop a deeper understanding of the relationships between urban configuration and design, locational externalities and property prices. New network analysis software tools such as Spatial Domain Network Analysis (SDNA) (http://www.cardiff.ac.uk/sdna/) provide a platform for the scientific study of associations between urban design and configuration on the one hand all manner of urban performance indicators such as land values, individual health and environmental quality and risk. 


\section{References}

ADAIR, A., MCGREAL, S., SMYTH, A., COOPER, J. \& RYLEY, T. 2000. House prices and accessibility: The testing of relationships within the Belfast urban area. Housing studies, 15, 699-716.

ALONSO, W. 1964. Location and land use: Toward a general theory of land rent. Publication of the Joint Center for Urban Studies. Harvard University Press.

BATTY, M. 2009. Accessibility: in search of a unified theory. Environment and Planning B: Planning and Design, 36, 191-194.

BELSLEY, D. A., KUH, E. \& WELSCH, R. E. 2005. Regression diagnostics: Identifying influential data and sources of collinearity, John Wiley \& Sons.

BYRNE, G., CHARLTON, M. \& FOTHERINGHAM, S. Multiple dependent hypothesis tests in geographically weighted regression. 10th International conference on geocomputation. UNSW, Sydney November-December, 2009.

CHIARADIA, A., HILLIER, B., SCHWANDER, C. \& WEDDERBURN, M. 2012. Compositional and urban form effects on centres in Greater London. Proceedings of the ICE-Urban Design and Planning, 165, 21-42.

CLIFF, A. D. \& ORD, J. K. 1981. Spatial processes: models \& applications, Pion London.

DEBREZION, G., PELS, E. \& RIETVELD, P. 2011. The Impact of Rail Transport on Real Estate Prices An Empirical Analysis of the Dutch Housing Market. Urban studies, 48, 997-1015.

DIEWERT, W. E. Hedonic regressions: a review of some unresolved issues. 2003. 29.

ENSTR M, R. \& NETZELL, O. 2008. Can space syntax help us in understanding the intraurban office rent pattern? Accessibility and rents in downtown Stockholm. The Journal of Real Estate Finance and Economics, 36, 289-305.

FOLLAIN, J. R. \& JIMENEZ, E. 1985. Estimating the demand for housing characteristics: a survey and critique. Regional science and urban economics, 15, 77-107.

FOTHERINGHAM, A. S., BRUNSDON, C. \& CHARLTON, M. 2003. Geographically weighted regression: the analysis of spatially varying relationships, John Wiley \& Sons.

FREEMAN, L. C. 1979. Centrality in social networks conceptual clarification. Social networks, 1, 215-239.

GIBBONS, S. \& MACHIN, S. 2005. Valuing rail access using transport innovations. Journal of Urban Economics, 57, 148-169.

HAGGETT, P. \& CHORLEY, R. J. 1969. Network analysis in geography. Edward Arnold (London).

HANSEN, W. G. 1959. How accessibility shapes land use. Journal of the American Institute of Planners, 25, 73-76.

HEIKKILA, E., GORDON, P., KIM, J. I., PEISER, R. B., RICHARDSON, H. W. \& DALEJOHNSON, D. 1989. What happened to the CBD-distance gradient? Land values in a policentric city. Environment and Planning A, 21, 221-232.

HILLIER, B. \& HANSON, J. 1984. The social logic of space, Cambridge University Press Cambridge.

HILLIER, B. \& PENN, A. 2004. Rejoinder to Carlo Ratti. Environment and Planning B: Planning and Design, 31, 501-511.

HOCH, I. \& WADDELL, P. 1993. Apartment rents: another challenge to the monocentric model. Geographical Analysis, 25, 20-34.

JIANG, B. \& CLARAMUNT, C. 2002. Integration of space syntax into GIS: new perspectives for urban morphology. Transactions in GIS, 6, 295-309.

JIANG, B. \& CLARAMUNT, C. 2004. Topological analysis of urban street networks. Environment and Planning B, 31, 151-162.

LANDAU, U., PRASHKER, J. N. \& HIRSH, M. 1981. The effect of temporal constraints on household travel behavior. Environment and Planning A, 13, 435-448.

MALPEZZI, S. 2003. Hedonic pricing models: a selective and applied review. Section in Housing Economics and Public Policy: Essays in Honor of Duncan Maclennan.

MATTHEWS, J. W. \& TURNBULL, G. K. 2007. Neighborhood street layout and property value: the interaction of accessibility and land use mix. The Journal of Real Estate Finance and Economics, 35, 111-141.

MCDONALD, J. F. 1987. The identification of urban employment subcenters. Journal of Urban 
Economics, 21, 242-258.

MILLS, E. S. 1972. Markets and efficient resource allocation in urban areas. The Swedish Journal of Economics, 100-113.

MUTH, R. F. 1969. CITIES AND HOUSING; THE SPATIAL PATTERN OF URBAN RESIDENTIAL LAND USE.

NIEDERCORN, J. H. \& AMMARI, N. S. 1987. New evidence on the specification and performance of neoclassical gravity models in the study of urban transportation. The Annals of Regional Science, 21, 56-64.

ORFORD, S. 2000. Modelling spatial structures in local housing market dynamics: a multilevel perspective. Urban Studies, 37, 1643.

ORFORD, S. 2002. Valuing locational externalities: a GIS and multilevel modelling approach. Environment and Planning B, 29, 105-128.

ORFORD, S. 2010. Towards a data-rich infrastructure for housing-market research: deriving floorarea estimates for individual properties from secondary data sources. Environment and planning. B, Planning \& design, 37, 248.

OSLAND, L. \& THORSEN, I. 2008. Effects on housing prices of urban attraction and labor-market accessibility. Environment and planning. A, 40, 2490.

PORTA, S., CRUCITTI, P. \& LATORA, V. 2006a. The network analysis of urban streets: a dual approach. Physica A: Statistical Mechanics and its Applications, 369, 853-866.

PORTA, S., CRUCITTI, P. \& LATORA, V. 2006b. The network analysis of urban streets: a primal approach. Environment and Planning B: Planning and Design, 33, 705-725.

PORTA, S., LATORA, V., WANG, F., RUEDA, S., STRANO, E., SCELLATO, S., CARDILLO, A., BELLI, E., CARDENAS, F. \& CORMENZANA, B. 2012. Street centrality and the location of economic activities in Barcelona. Urban Studies, 49, 1471-1488.

PORTA, S., LATORA, V., WANG, F., STRANO, E., CARDILLO, A., SCELLATO, S., IACOVIELLO, V. \& MESSORA, R. 2009. Street centrality and densities of retail and services in Bologna, Italy. Environment and Planning B: Planning and Design, 36, 450-465.

RATTI, C. 2004. Urban texture and space syntax: some inconsistencies. Environment and Planning B: Planning and Design, 31, 487-499.

RICHARDSON, H. W., GORDON, P., JUN, M., HEIKKILA, E., PEISER, R. \& DALE-JOHNSON, D. 1990. Residential property values, the CBD, and multiple nodes: further analysis. Environment and Planning A, 22, 829-833.

SIRMANS, G. S., MACDONALD, L., MACPHERSON, D. A. \& ZIETZ, E. N. 2006. The value of housing characteristics: a meta analysis. The Journal of Real Estate Finance and Economics, 33, 215-240.

SIRMANS, S. G., MACPHERSON, D. A. \& ZIETZ, E. N. 2005. The composition of hedonic pricing models. Journal of Real Estate Literature, 13, 1-44.

STEADMAN, P. 2004. Developments in space syntax. Environment and Planning B: Planning and Design, 31, 483-486.

STEWART, J. Q. 1947. Empirical mathematical rules concerning the distribution and equilibrium of population. Geographical Review, 37, 461-485.

TURNER, A. 2007. From axial to road-centre lines: a new representation for space syntax and a new model of route choice for transport network analysis. Environment and Planning B: Planning and Design, 34, 539-555.

TURNER, A., PENN, A. \& HILLIER, B. 2005. An algorithmic definition of the axial map. Environment and Planning B: Planning and Design, 32, 425-444.

VICKERS, D. \& REES, P. 2007. Creating the UK National Statistics 2001 output area classification. Journal of the Royal Statistical Society: Series A (Statistics in Society), 170, 379-403.

WADDELL, P., BERRY, B. J. L. \& HOCH, I. 1993. Housing price gradients: The intersection of space and built form. Geographical Analysis, 25, 5-19.

WEBSTER, C. 2010. Pricing accessibility: Urban morphology, design and missing markets. Progress in Planning, 73, 77-111.

WOO, Y. \& WEBSTER, C. 2013. Co-evolution of gated communities and local public goods. Urban Studies, 0042098013510565. 
Figure 1: The city of Cardiff, Wales and the case study area (Ordnance Survey @Crown Copyright. All rights reserved)

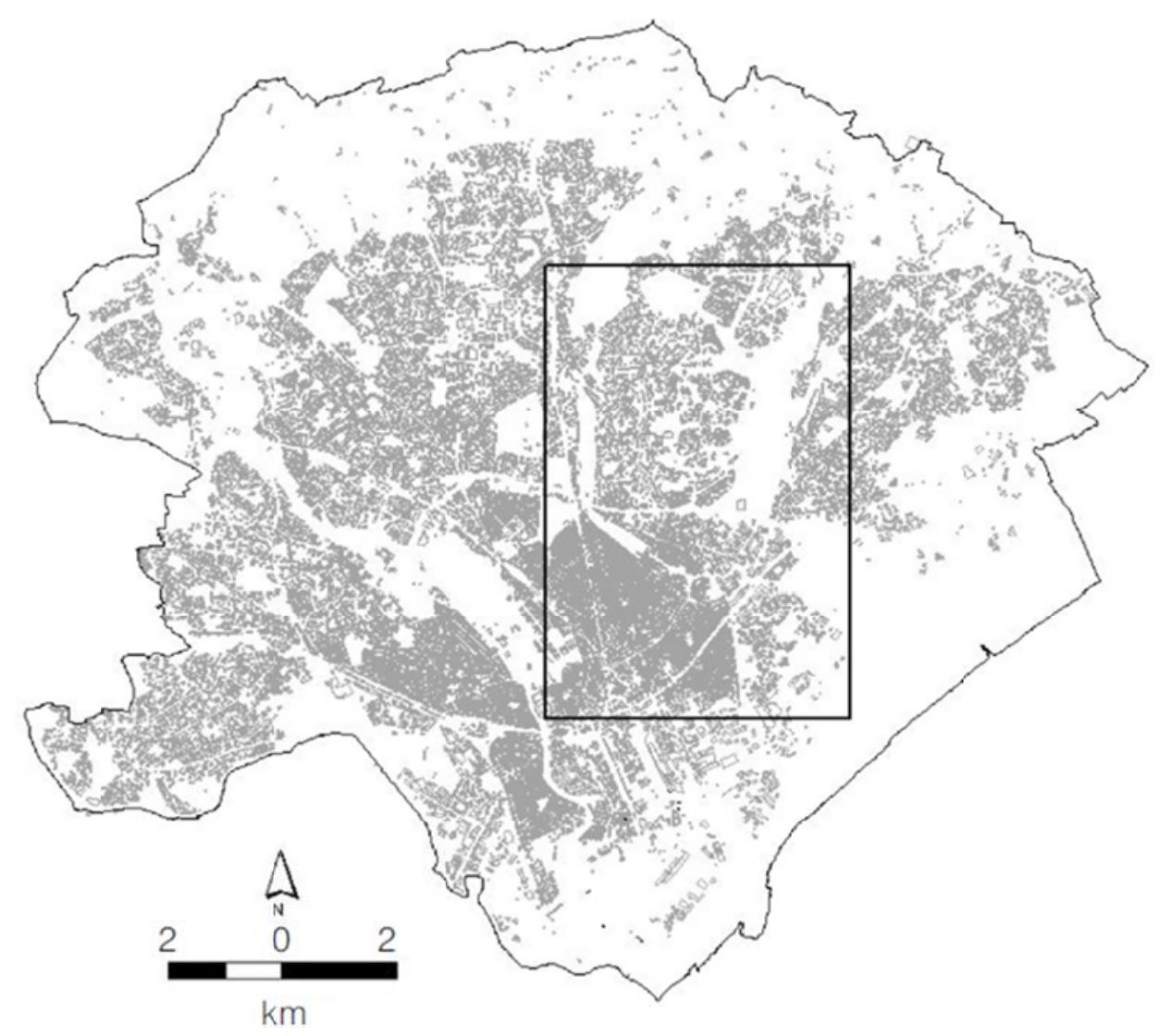


Table 1: Description of the variables (property level)

\begin{tabular}{|c|c|c|c|c|c|c|}
\hline Variables & Description & Type & Min & Max & Mean & SDev \\
\hline LN_FL & Natural log of floor area & Continuous & 1.793 & 9.595 & 4.903 & 1.071 \\
\hline LN_CBD & Natural log of distance to City Centre & Continuous & -0.66 & 1.79 & 0.76 & 0.62 \\
\hline LN_BAY & Natural log of distance to Cardiff bay & Continuous & 0.93 & 2.18 & 1.6 & 0.29 \\
\hline LN_ROATH & Natural log of distance to Roath Park & Continuous & -3.19 & 1.52 & 0.72 & 0.52 \\
\hline LN_HOSP & Natural log of distance to Heath hospital & Continuous & -0.42 & 1.82 & 0.99 & 0.48 \\
\hline LN_BUTE & Natural log of distance to Bute Park & Continuous & -1.03 & 1.64 & 0.95 & 0.39 \\
\hline BE_R400M & Betweenness value at radius $400 \mathrm{~m}$ & Continuous & 0 & 3.183 & 1.483 & 0.923 \\
\hline BE_R800M & Betweenness value at radius $800 \mathrm{~m}$ & Continuous & 0 & 3.879 & 2.152 & 1.277 \\
\hline BE_R1200M & Betweenness value at radius $1200 \mathrm{~m}$ & Continuous & 0 & 4.464 & 2.51 & 1.485 \\
\hline BE_R1600M & Betweenness value at radius $1600 \mathrm{~m}$ & Continuous & 0 & 4.961 & 2.745 & 1.626 \\
\hline BE_R2000M & Betweenness value at radius $2000 \mathrm{~m}$ & Continuous & 0 & 5.287 & 2.912 & 1.721 \\
\hline BE_R2500M & Betweenness value at radius $2500 \mathrm{~m}$ & Continuous & 0 & 5.57 & 3.069 & 1.817 \\
\hline BE_R3000M & Betweenness value at radius $3000 \mathrm{~m}$ & Continuous & 0 & 5.789 & 3.195 & 1.891 \\
\hline BE_R4000M & Betweenness value at radius $4000 \mathrm{~m}$ & Continuous & 0 & 6.155 & 3.389 & 2.004 \\
\hline BE_R5000M & Betweenness value at radius $5000 \mathrm{~m}$ & Continuous & 0 & 6.43 & 3.529 & 2.091 \\
\hline BE_R6000M & Betweenness value at radius $6000 \mathrm{~m}$ & Continuous & 0 & 6.655 & 3.634 & 2.161 \\
\hline BE_R7000M & Betweenness value at radius $7000 \mathrm{~m}$ & Continuous & 0 & 6.887 & 3.719 & 2.209 \\
\hline BE_R8000M & Betweenness value at radius $8000 \mathrm{~m}$ & Continuous & 0 & 7.058 & 3.778 & 2.249 \\
\hline BE_R10000M & Betweenness value at radius $10000 \mathrm{~m}$ & Continuous & 0 & 7.273 & 3.834 & 2.295 \\
\hline BE_N & Betweenness value for city wide & Continuous & 0 & 7.567 & 3.834 & 2.337 \\
\hline CL_R400M & Closeness value at radius $400 \mathrm{~m}$ & Continuous & 0 & 95.898 & 29.479 & 16.135 \\
\hline CL_R800M & Closeness value at radius $800 \mathrm{~m}$ & Continuous & 0 & 194.551 & 68.402 & 40.154 \\
\hline CL_R1200M & Closeness value at radius $1200 \mathrm{~m}$ & Continuous & 11.928 & 350.988 & 120.269 & 67.933 \\
\hline CL_R1600M & Closeness value at radius $1600 \mathrm{~m}$ & Continuous & 16.489 & 482.002 & 181.727 & 97.358 \\
\hline CL_R2000M & Closeness value at radius $2000 \mathrm{~m}$ & Continuous & 26.903 & 576.524 & 246.244 & 125.338 \\
\hline CL_R2500M & Closeness value at radius $2500 \mathrm{~m}$ & Continuous & 30.971 & 719.865 & 327.692 & 155.646 \\
\hline CL_R3000M & Closeness value at radius $3000 \mathrm{~m}$ & Continuous & 44.303 & 825.042 & 411.021 & 181.137 \\
\hline CL_R4000M & Closeness value at radius $4000 \mathrm{~m}$ & Continuous & 77.035 & 1044.48 & 584.539 & 219.047 \\
\hline CL_R5000M & Closeness value at radius $5000 \mathrm{~m}$ & Continuous & 141.572 & 1317.72 & 763.448 & 254.955 \\
\hline CL_R6000M & Closeness value at radius $6000 \mathrm{~m}$ & Continuous & 251.813 & 1604.22 & 944.528 & 281.435 \\
\hline CL_R7000M & Closeness value at radius $7000 \mathrm{~m}$ & Continuous & 359.996 & 1793.71 & 1114.311 & 298.407 \\
\hline CL_R8000M & Closeness value at radius $8000 \mathrm{~m}$ & Continuous & 441.707 & 1939.79 & 1248.791 & 308.14 \\
\hline CL_R10000M & Closeness value at radius $10000 \mathrm{~m}$ & Continuous & 616.409 & 2107.21 & 1412.711 & 292.122 \\
\hline CL_N & Closeness value for city wide & Continuous & 858.122 & 2150.76 & 1521.65 & 245.688 \\
\hline
\end{tabular}

\begin{tabular}{lllrcrc}
\hline Variables & Description & Type & $\begin{array}{l}\text { Code 0 } \\
\text { (\%) }\end{array}$ & $\begin{array}{l}\text { Code 1 } \\
\text { (\%) }\end{array}$ & Mean & SDev \\
\hline DU_NEW & New Build & Dummy & 92.9 & 7.1 & 0.080 & 0.268 \\
DU_DET & Detached House & Dummy & 91.2 & 8.8 & 0.100 & 0.300 \\
DU_SEMI & Semidetached House & Dummy & 79.2 & 20.8 & 0.210 & 0.407 \\
DU_TER & Terrace house & Dummy & 46.6 & 53.4 & 0.520 & 0.500 \\
DU_FLAT & Flat & Dummy & 83 & 17.0 & 0.170 & 0.375 \\
DU_TEN & Tenure ( Freehold=1 Leasehold =0) & Dummy & 21.7 & 78.3 & 0.790 & 0.411 \\
DU_BC & OAC Blue collar communities & Dummy & 89.1 & 10.9 & 0.110 & 0.310 \\
DU_CL & OAC Living in the city & Dummy & 72 & 28.0 & 0.270 & 0.446
\end{tabular}




\begin{tabular}{lllrrrr} 
DU_PS & OAC Prosperous suburbs & Dummy & 87 & 13.0 & 0.150 & 0.354 \\
DU_CC & OAC Constrained by Circumstances & Dummy & 95.5 & 4.5 & 0.050 & 0.208 \\
DU_TT & OAC Typical traits & Dummy & 71.7 & 28.3 & 0.280 & 0.449 \\
DU_MU & OAC Multicultural & Dummy & 84.7 & 15.3 & 0.150 & 0.353 \\
Y2000 & Transactions in 2000 & Dummy & 89.3 & 10.7 & 0.110 & 0.309 \\
Y2001 & Transactions in 2001 & Dummy & 86.6 & 13.4 & 0.130 & 0.340 \\
Y2002 & Transactions in 2002 & Dummy & 85 & 15.0 & 0.150 & 0.359 \\
Y2003 & Transactions in 2003 & Dummy & 86.7 & 13.3 & 0.130 & 0.339 \\
Y2004 & Transactions in 2004 & Dummy & 87.5 & 12.5 & 0.130 & 0.332 \\
Y2005 & Transactions in 2005 & Dummy & 90.2 & 9.8 & 0.100 & 0.301 \\
Y2006 & Transactions in 2006 & Dummy & 87.6 & 12.4 & 0.120 & 0.328 \\
Y2007 & Transactions in 2007 & Dummy & 88.2 & 11.8 & 0.120 & 0.321 \\
Y2008 & Transactions in 2008 & Dummy & 98.9 & 1.1 & 0.010 & 0.099 \\
\hline
\end{tabular}


Table 2: Model I the conventional hedonic model with geometric accessibility variables

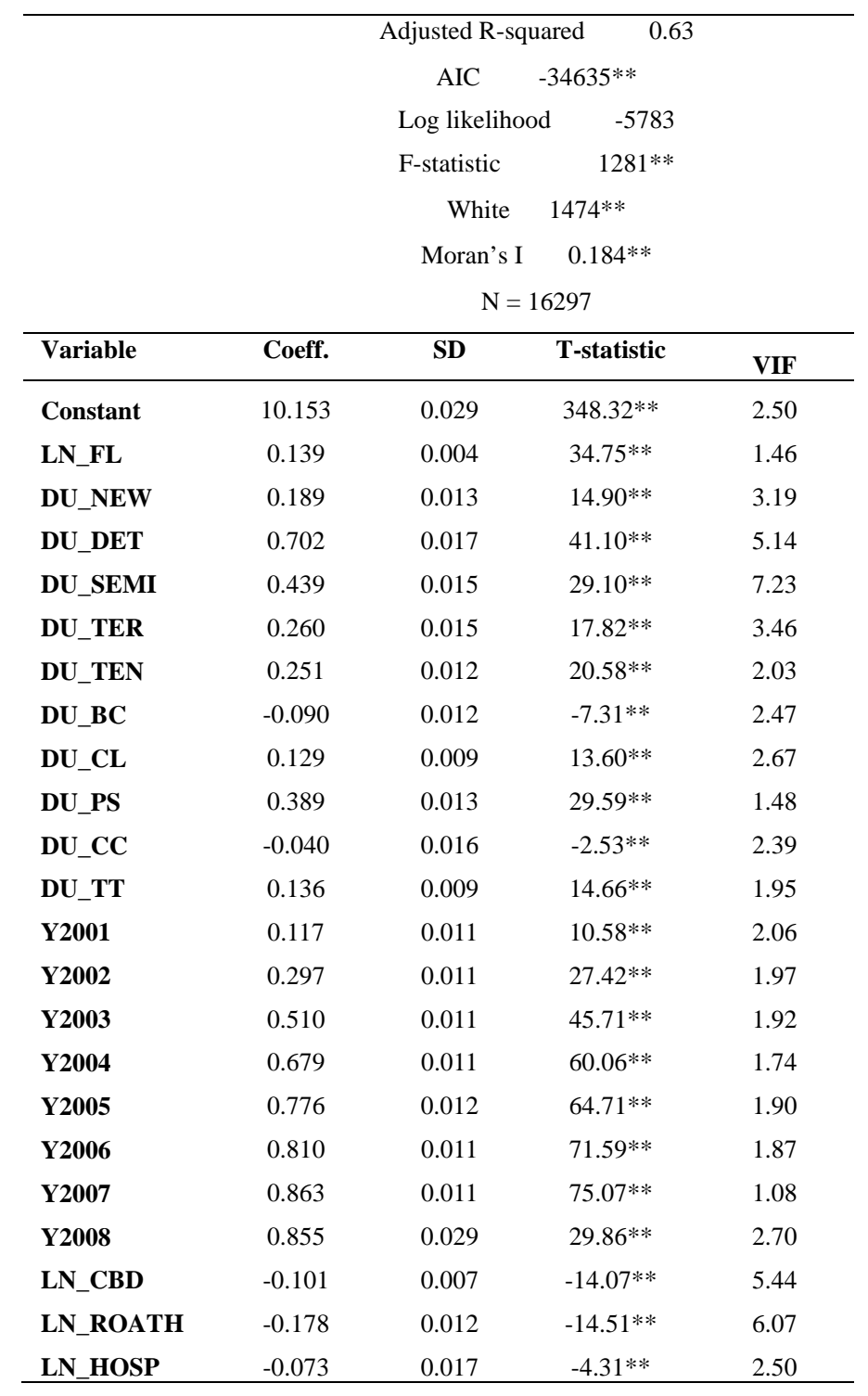

* Significant at $5 \%$ level or less

** Significant at $1 \%$ level or less 
Table 3: Model II the conventional hedonic model with space syntax accessibility variables

Different Radii - T -statistic comparisons

\begin{tabular}{|c|c|c|c|c|c|c|c|c|c|c|c|c|c|c|}
\hline & \multicolumn{2}{|c|}{$400 M$} & \multicolumn{2}{|c|}{$800 M$} & \multicolumn{2}{|c|}{$1200 \mathrm{M}$} & \multicolumn{2}{|c|}{$1600 M$} & \multicolumn{2}{|c|}{$2000 \mathrm{M}$} & \multicolumn{2}{|c|}{$2500 M$} & \multicolumn{2}{|c|}{$3000 \mathrm{M}$} \\
\hline & BE & CL & BE & CL & $\mathbf{B E}$ & CL & BE & CL & $\mathbf{B E}$ & CL & BE & CL & BE & CI \\
\hline Coef & -0.018 & 0.003 & -0.016 & 0.002 & -0.017 & 0.002 & -0.018 & 0.001 & -0.019 & 0.1001 & -0.017 & 0.001 & -0.016 & 0.00 \\
\hline $\mathbf{T}$ & $-4.22 * *$ & $10.35^{* *}$ & $-5.58 * *$ & $19.77 * *$ & $-7.14^{* *}$ & $25.16^{* *}$ & $-8.86^{* *}$ & $30.05^{* *}$ & $-9.87 * *$ & $34.183^{* *}$ & $-9.65^{* *}$ & $36.77 * *$ & $-9.38 * *$ & 37.05 \\
\hline AIC & \multicolumn{2}{|c|}{-33123} & \multicolumn{2}{|c|}{-33432} & \multicolumn{2}{|c|}{-33668} & \multicolumn{2}{|c|}{-33931} & \multicolumn{2}{|c|}{-34223} & \multicolumn{2}{|c|}{-34355} & \multicolumn{2}{|c|}{-34371} \\
\hline White & \multicolumn{2}{|c|}{$1432 * *$} & \multicolumn{2}{|c|}{$1306^{* *}$} & \multicolumn{2}{|c|}{$1221^{* *}$} & \multicolumn{2}{|c|}{$1179 * *$} & \multicolumn{2}{|c|}{$1095^{* *}$} & \multicolumn{2}{|c|}{$1137^{* *}$} & \multicolumn{2}{|c|}{$1095^{* *}$} \\
\hline Moran I & \multicolumn{2}{|c|}{$0.175^{* *}$} & \multicolumn{2}{|c|}{$0.174 * *$} & \multicolumn{2}{|c|}{$0.173^{* *}$} & \multicolumn{2}{|c|}{$0.171^{* *}$} & \multicolumn{2}{|c|}{$0.168^{* *}$} & \multicolumn{2}{|c|}{$0.168 * *$} & \multicolumn{2}{|c|}{$0.165^{* *}$} \\
\hline & \multicolumn{2}{|c|}{$4000 \mathrm{M}$} & \multicolumn{2}{|c|}{$5000 \mathrm{M}$} & \multicolumn{2}{|c|}{$6000 M$} & \multicolumn{2}{|c|}{$7000 \mathrm{M}$} & \multicolumn{2}{|c|}{$8000 M$} & \multicolumn{2}{|c|}{$10000 \mathrm{M}$} & \multicolumn{2}{|c|}{ City-wide } \\
\hline & BE & CL & BE & CL & BE & CL & BE & CL & BE & CL & BE & CL & BE & CI \\
\hline Coef & -0.014 & 0.001 & -0.013 & 0.001 & -0.014 & 0.001 & -0.016 & 0.001 & -0.015 & 0.1001 & -0.014 & 0 & -0.016 & 0.00 \\
\hline $\mathbf{T}$ & $-8.83^{* *}$ & $35.61 * *$ & $-8.61^{* *}$ & $35.24 * *$ & $-9.70 * *$ & $38.06^{* *}$ & $-10.93 * *$ & $40.49 * *$ & $-10.75^{* *}$ & $39.155^{* *}$ & $-10.15^{* *}$ & $36.69 * *$ & $-10.98 * *$ & 33.12 \\
\hline AIC & & 272 & & 248 & & 437 & -34 & & -34 & & -34 & & -34 & \\
\hline White & 10 & $5 * *$ & 11 & $7 * *$ & & $9^{* *}$ & 122 & & 126 & & 130 & & 130 & ;** \\
\hline Moran I & 0.1 & $7 * *$ & 0.1 & $8 * *$ & 0.1 & $8 * *$ & 0.17 & & 0.17 & & 0.17 & & 0.17 & $3 * *$ \\
\hline
\end{tabular}

A set of explanatory variables have been included in the regression model but are not reported in the table for the sake of brevity

R-sq (adj) 0.63

* Significant at $5 \%$ level or less

** Significant at $1 \%$ level or less

Figure 2: T-statistics of the space syntax accessibility variables estimated in Model II for different spatial scales

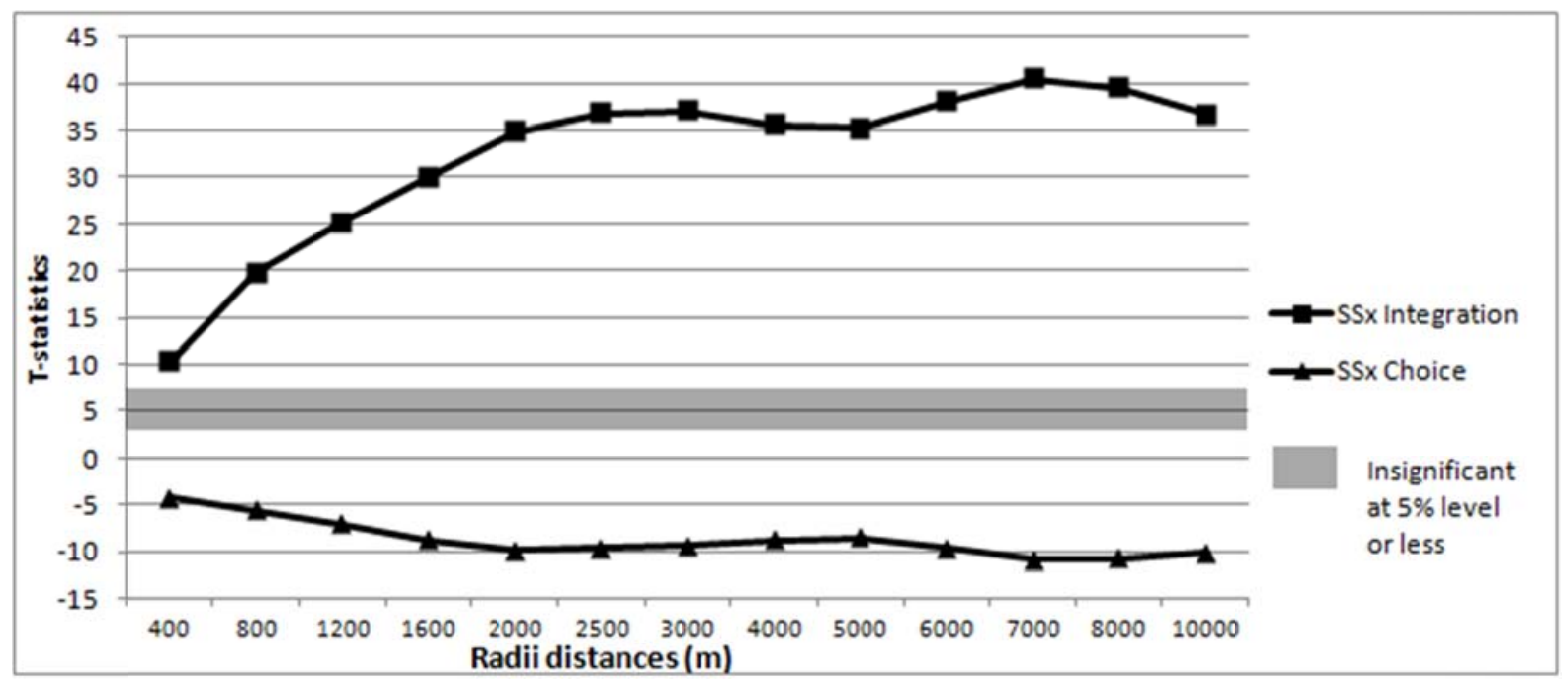


Table 4: Model III the conventional hedonic model with geometric and space syntax accessibility variables

Different Radii - T -statistic comparisons

\begin{tabular}{|c|c|c|c|c|c|c|c|c|c|c|c|c|}
\hline & \multicolumn{2}{|c|}{400} & \multicolumn{2}{|c|}{800} & \multicolumn{2}{|c|}{1200} & \multicolumn{2}{|c|}{1600} & \multicolumn{2}{|c|}{2000} & \multicolumn{2}{|c|}{2500} \\
\hline & B & $\mathbf{T}$ & B & $\mathbf{T}$ & B & $\mathbf{T}$ & B & $\mathbf{T}$ & B & $\mathbf{T}$ & B & $\mathbf{T}$ \\
\hline LN_CBD & -0.09 & $12 . \overline{7} 0^{\star \star}$ & -0.08 & $10 . \overline{2} 6^{\star \star}$ & -0.06 & $-7.53^{\star \star}$ & -0.03 & $-4.01^{\star \star}$ & $0 . \overline{01}$ & -0.95 & 0.01 & 1.06 \\
\hline LN_ROATH & -0.19 & $15.17^{\star \star}$ & -0.20 & $16.58^{\star *}$ & -0.20 & $16.67^{\star \star}$ & -0.20 & $16.45^{\star \star}$ & 0.20 & $16.41^{\star *}$ & -0.19 & $16.16^{\star \star}$ \\
\hline LN_HOSP & $\begin{array}{c}-0.05 \\
-\end{array}$ & $-3.19^{\star \star}$ & -0.02 & -1.15 & -0.01 & -0.56 & 0.002 & -0.09 & $\begin{array}{c}0.01 \\
-\end{array}$ & 0.81 & 0.02 & 1.21 \\
\hline BE & 0.005 & -1.18 & -0.01 & $-3.18^{\star *}$ & -0.01 & $-4.40^{* *}$ & -0.01 & $-5.79 * *$ & 0.01 & $-6.86^{\star *}$ & -0.01 & $-6.71^{\star *}$ \\
\hline $\mathrm{CL}$ & 0.001 & $4.98^{\star \star}$ & 0.001 & $13.68^{\star \star}$ & 0.001 & $17.43^{\star \star}$ & 0.001 & $20.99^{\star *}$ & 0.00 & $25.08^{\star \star}$ & 0.001 & $26.47^{* \star}$ \\
\hline AIC & \multicolumn{2}{|c|}{-34659} & \multicolumn{2}{|c|}{-34845} & \multicolumn{2}{|c|}{-34956} & \multicolumn{2}{|c|}{-35094} & \multicolumn{2}{|c|}{-35276} & \multicolumn{2}{|c|}{-35346} \\
\hline White & \multicolumn{2}{|c|}{$1432^{* *}$} & \multicolumn{2}{|c|}{$1390^{* *}$} & \multicolumn{2}{|c|}{$1306^{* *}$} & \multicolumn{2}{|c|}{$1179 * *$} & \multicolumn{2}{|c|}{$1095^{* *}$} & \multicolumn{2}{|c|}{$1137^{* *}$} \\
\hline \multirow[t]{3}{*}{ Moran I } & \multicolumn{2}{|c|}{$0.175^{* *}$} & \multicolumn{2}{|c|}{$0.170^{* *}$} & \multicolumn{2}{|c|}{$0.168^{* *}$} & \multicolumn{2}{|c|}{$0.165^{* *}$} & \multicolumn{2}{|c|}{$0.165^{* *}$} & \multicolumn{2}{|c|}{$0.163^{* *}$} \\
\hline & \multicolumn{2}{|c|}{3000} & \multicolumn{2}{|c|}{4000} & \multicolumn{2}{|c|}{5000} & \multicolumn{2}{|c|}{6000} & \multicolumn{2}{|c|}{7000} & \multicolumn{2}{|c|}{8000} \\
\hline & B & $\mathbf{T}$ & B & $\mathbf{T}$ & B & $\mathbf{T}$ & B & $\mathbf{T}$ & B & $\mathbf{T}$ & B & $T$ \\
\hline LN_CBD & 0.02 & $2.07^{\star}$ & 0.02 & $2.03^{*}$ & 0.02 & $2.03^{*}$ & 0.003 & -0.40 & 0.004 & 0.51 & 0.01 & 0.62 \\
\hline LN_ROATH & -0.19 & $15.85^{\star \star}$ & -0.19 & $15.71^{\star \star}$ & -0.19 & $15.71^{\star *}$ & -0.20 & $16.27^{\star \star}$ & -0.20 & $16.51^{\star \star}$ & -0.20 & $16.62^{\star \star}$ \\
\hline LN_HOSP & 0.02 & 1.17 & 0.01 & 0.74 & 0.01 & 0.74 & 0.05 & $2.61^{\star \star}$ & 0.07 & $4.09^{\star \star}$ & 0.07 & $4.25^{\star \star}$ \\
\hline BE & -0.01 & $-6.49^{* *}$ & -0.01 & $-6.00 * *$ & -0.01 & $-6.00 * *$ & -0.01 & $-5.92^{\star \star}$ & -0.01 & $-7.07^{* *}$ & -0.01 & $-6.76^{\star *}$ \\
\hline $\mathrm{CL}$ & 0.001 & $26.42^{\star \star}$ & 0.001 & $25.03^{\star \star}$ & 0.001 & $25.03^{\star \star}$ & 0.000 & $24.42^{\star \star}$ & 0.000 & $25.84^{\star \star}$ & 0.000 & $24.30^{\star \star}$ \\
\hline AIC & \multicolumn{2}{|c|}{-35346} & \multicolumn{2}{|c|}{-35276} & & 206 & & 241 & & 302 & & 5224 \\
\hline White & & $7^{* *}$ & & $79 * *$ & & $1 * *$ & & $21^{* *}$ & & $33 * *$ & & $48^{* *}$ \\
\hline Moran I & 0.1 & $52 * *$ & 0.1 & $65 * *$ & 0.1 & $67 * *$ & & $68 * *$ & & $70 * *$ & & $71^{* *}$ \\
\hline
\end{tabular}

\begin{tabular}{|c|c|c|c|c|}
\hline & \multicolumn{2}{|c|}{10000} & \multicolumn{2}{|c|}{ city } \\
\hline & B & $\mathbf{T}$ & B & $\mathbf{T}$ \\
\hline LN_CBD & -0.02 & $-2.24^{*}$ & -0.05 & $-6.29^{\star *}$ \\
\hline LN_ROATH & -0.19 & $15.88^{\star *}$ & -0.20 & $16.55^{\text {** }}$ \\
\hline LN_HOSP & 0.04 & $2.31^{*}$ & 0.03 & 1.63 \\
\hline $\mathrm{BE}$ & -0.01 & $-5.19^{\star *}$ & -0.01 & $-5.40^{* *}$ \\
\hline CL & 0.000 & $20.49^{* *}$ & 0.000 & $18.39^{* *}$ \\
\hline AIC & \multicolumn{2}{|c|}{-35068} & \multicolumn{2}{|c|}{-34990} \\
\hline White & \multicolumn{2}{|c|}{$1390 * *$} & \multicolumn{2}{|c|}{$1390 * *$} \\
\hline Moran I & \multicolumn{2}{|c|}{$0.171^{* *}$} & \multicolumn{2}{|c|}{$0.172^{* *}$} \\
\hline
\end{tabular}

A set of explanatory variables have been included in the regression model but are not reported in the table for the sake of brevity

R-sq (adj) 0.65

* Significant at $5 \%$ level or less

** Significant at $1 \%$ level or less 
Figure 3: T-statistics of the space syntax accessibility variables estimated in Model III for different spatial scales

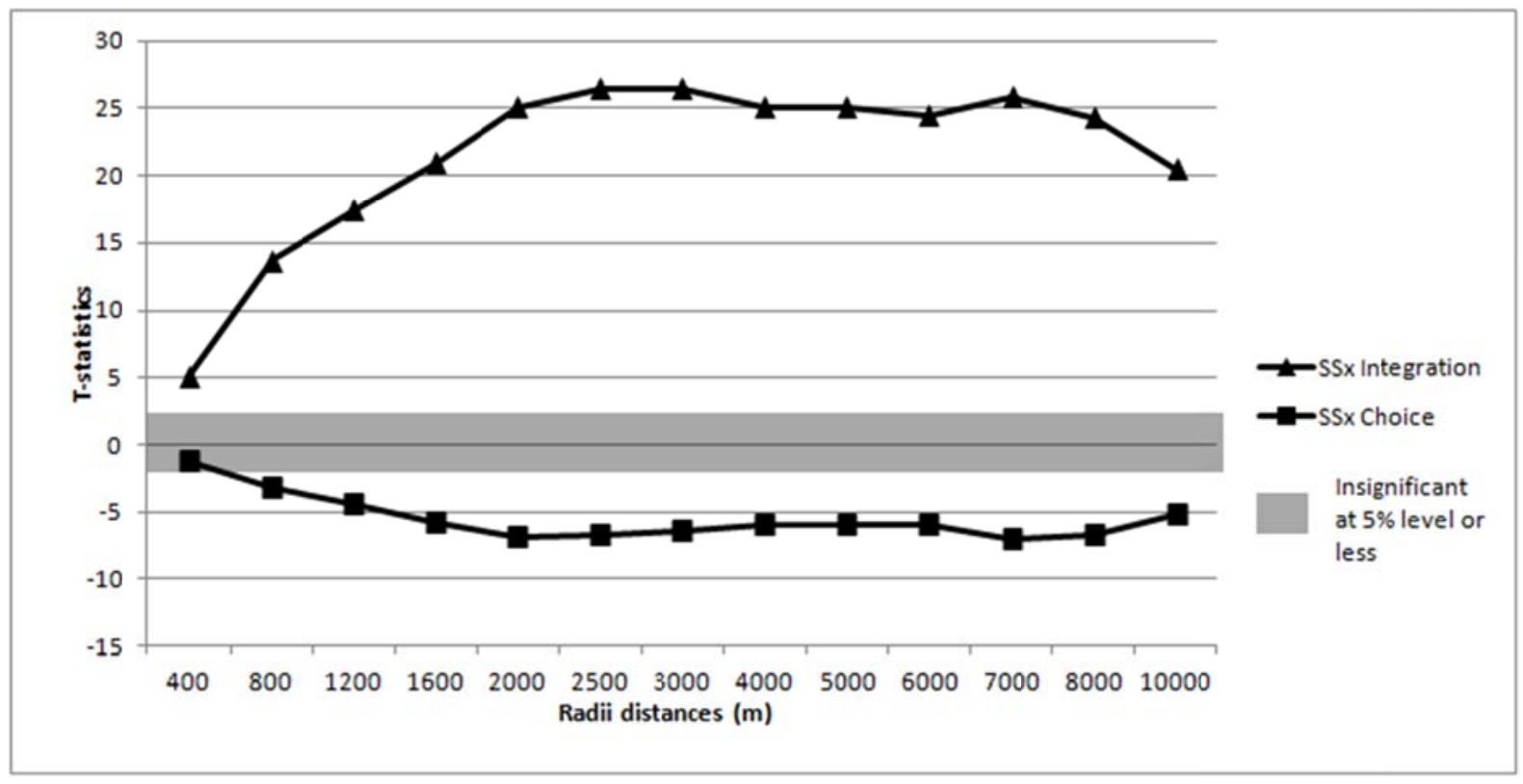

Figure 4: T-statistics of the geometric accessibility variables estimated in Model III for different spatial scales

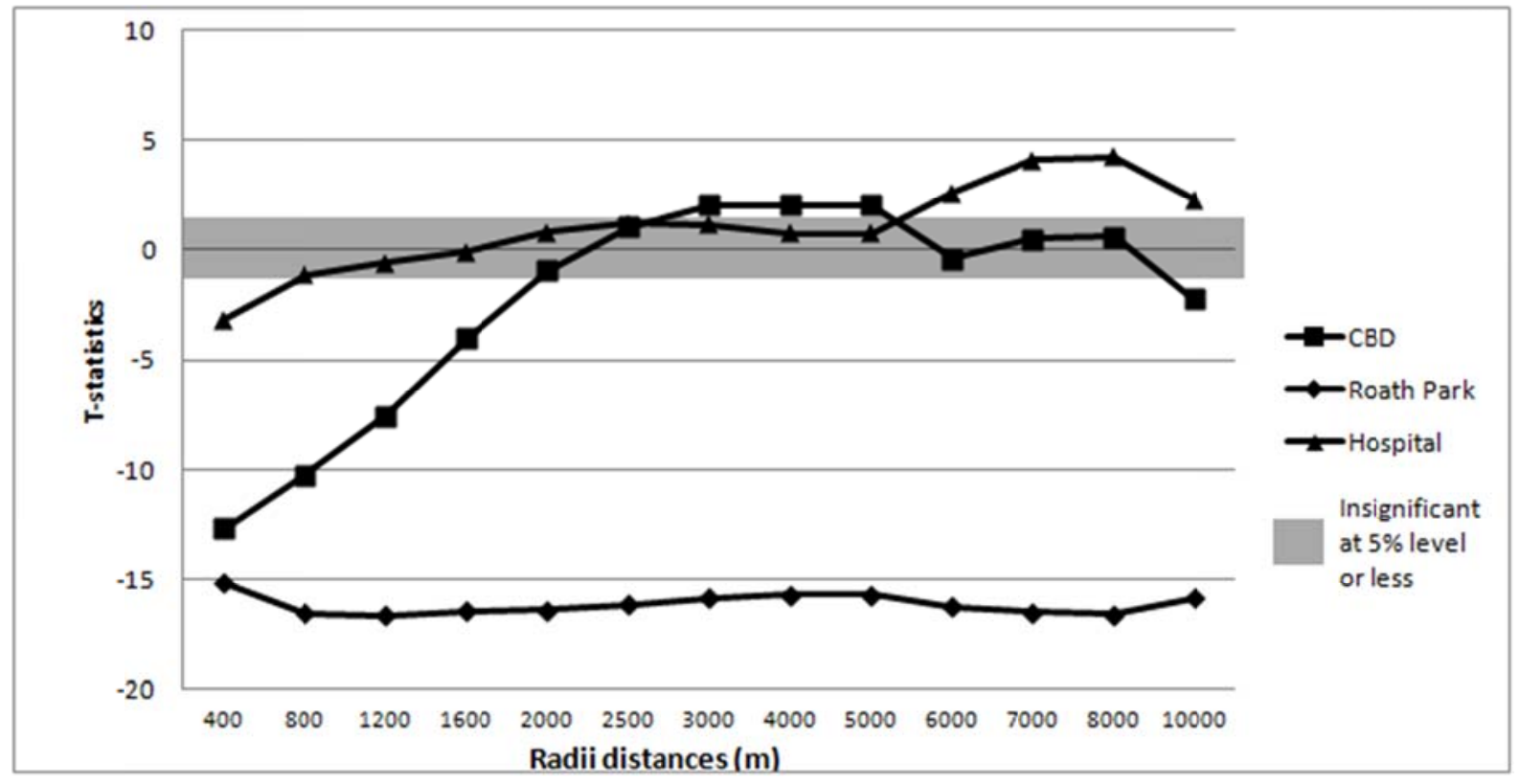




\section{List of Tables}

Table 1: Description of the variables (property level)

Table 2: Model I the conventional hedonic model with geometric accessibility variables

Table 3: Model II the conventional hedonic model with space syntax accessibility variables

Table 4: Model III the conventional hedonic model with geometric and space syntax accessibility variables

\section{List of Figures}

Figure 1: The city of Cardiff, Wales and the case study area (Ordnance Survey CCrown Copyright. All rights reserved)

Figure 2: T-statistics of the space syntax accessibility variables estimated in Model II for different spatial scales

Figure 3: T-statistics of the space syntax accessibility variables estimated in Model III for different spatial scales

Figure 4: T-statistics of the geometric accessibility variables estimated in Model III for different spatial scales 